\title{
Yubaka Hayrá: Notas sobre a Conferência Indígena da Ayahuasca
}

\author{
DOMINGOS BUENO DA SILVA
}

A primeira Conferência Indígena da Ayahuasca ${ }^{1}$ - Yubaka Hayrá -, que na língua Hãtxa Kuin significa algo como "todos juntos conversando sobre o que é certo", foi um evento realizado entre 14 a 17 de dezembro de 2017 na Terra Indígena Puyanawa, localizada na cidade de Mâncio Lima, no estado do Acre, com a participação de mais de 170 indígenas, representando 14 povos. O evento teve como objetivo discutir aspectos ligados à produção, transporte, consumo, patrimonialização, questões relacionadas à ancestralidade, preparo e utilização da ayahuasca pelos povos indígenas ${ }^{2}$.

Organizada por algumas organizações indígenas do Acre como a Organização dos Povos Indígenas do Rio Envira (Opire), Organização dos Povos Indígenas de Tarauacá (Opitar), Organização dos Povos Indígenas do Rio Jordão (Opirj) e a Associação dos Seringueiros Kaxinawá do Rio Jordão (ASKARJ), além do apoio logístico do Instituto Federal do Acre (Ifac) e da Fundação Nacional do Índio (Funai/CR Juruá) ${ }^{3}$, as várias discussões e painéis apresentados constituíram-se em formato de contraponto aos desdobramentos, deliberações e direcionamentos das duas edições da AYA: World

\footnotetext{
1 A ayahuasca, palavra de origem quechua para vinho das almas, é um chá obtido pela cocção de duas espécies vegetais originalmente amazônicas, o cipó Banisteriopsis caapi e o arbusto Psychotria viridis. Utilizado milenarmente por várias sociedades indígenas da Amazônia para produzir estados alterados de consciência, tornou-se conhecido dos não índios brasileiros nos sucessivos ciclos da borracha, que originaram diversas religiões ayahuasqueiras e usam o chá em seus rituais. Seus seguidores hoje em dia se espalham não apenas pelo Brasil, mas em vários países.
}

2 Sobre a ayahuasca no universo indígena e urbano ver Luna (1986), Groissman (1991), Labate (2002, 2017), Räatsch (2005), Mizumoto (2012) e outros.

3 Participaram os povos Apolima Arara, Ashaninka, Huni Kuin, Jaminawa, Jaminawá Arara, Kuntanawa, Manxineru, Nawa, Noke Koi, Nukini Puyanawa, Shanenawa, Shawãdawa, Yawanawá e Tukano do Amazonas, representado por Daiara Tukano da Radio Yande. Além dos organizadores, outras organizações também participaram do encontro como a Associação do Movimento dos Agentes Agroflorestais Indígenas do Acre (Amaaiac), Organização dos Professores Indígenas do Acre (Opiac), Organização das Mulheres Indígenas do Acre, Sul do Amazonas e Noroeste de Rondônia (Sitoakore), Federação do Povo Huni Kuin do Acre (Fephac), Conselho Nacional de Políticas Indigenistas (CNPI), Instituto do Patrimônio Histórico e Artístico Nacional (Iphan). Empresa Brasileira de Pesquisa Agropecuária (Embrapa); Assessoria de Assuntos Indígenas do Estado do Acre e o Distrito Sanitário Especial Indígena do Alto Juruá (Dsei/ARJ). 
Ayahuasca Conference, que não contemplaram os questionamentos e encaminhamentos dos povos indígenas da Amazônia ${ }^{4}$.

A primeira edição da AYA aconteceu em 2014 na cidade de Ibiza, Espanha, organizada pelo International Center for Ethnobotanical Education, Research and Service (Iceers), voltada para um público predominantemente científico, junto a representantes de igrejas ayahuasqueiras, com uma pequena participação de representantes indígenas. Na época a imprensa local espanhola chegou a chamar Ibiza de "a capital internacional da ayahuasca", gerando óbvias notas de indignação sobre a apropriação que então se processava 5 .

Sua segunda edição em Rio Branco em parceria com a Universidade Federal do Acre, Ufac, foi também uma tentativa de aproximar a comunidade científica, as igrejas ayahuasqueiras e os índios num evento de grande porte, buscando superar o mal-estar da primeira edição espanhola. Infelizmente, no entanto, a quase totalidade dos temas discutidos durante a AYA não contemplaram ou divergiram essencialmente dos posicionamentos dos indígenas.

Entre as queixas relatadas, inclusive nas redes sociais, pelos poucos participantes indígenas presentes no evento, a principal foi em relação ao formato e ao curto tempo de exposição nas mesas, característico dos congressos acadêmicos, que impossibilita o desenvolvimento de um outro tipo de argumentação que não se orienta pela síntese temática dos grupos de trabalho, mas que desenvolve-se por meio das habilidades de oratória e da performance da fala, características de várias sociedades ameríndias. Normalmente divididas em GTs temáticos com blocos de 15 minutos, as apresentações não comportam esse tipo de expressão e formalização retórica que, em sua forma nativa, pode estender-se por horas ou ser fragmentada ao longo dos dias e noites.

Outra crítica foi com relação ao tratamento desigual oferecido aos palestrantes indígenas e não indígenas. Estudiosos e mestres dos saberes da floresta sofreram tratamento assimétrico em relação aos demais palestrantes, muitos deles estrangeiros, acomodados em hotéis de Rio Branco, com deslocamento e alimentação diferenciada, enquanto que os índios foram distribuídos em alojamentos universitários, alimentando-se no refeitório da instituição hospedeira. Em assembleias e encontros promovidos pelas organizações indígenas, e com a crescente dificuldade de conseguir recursos para os eventos, as acomodações seriam consideradas suficientes. De um modo geral, os povos da floresta são reconhecidos por sua capacidade de despojamento e adaptação às diversidades que enfrentam, então essa não seria a principal questão.

O que ali se evidenciou para os índios foi o reconhecimento dos organizadores do protagonismo do pensamento científico acadêmico e eurocêntrico no evento, além do papel reconhecidamente

4 O resumo de Labate sobre o evento nos permite um vislumbre de sua magnitude, com mais de 200 propostas compostas por $60 \%$ de pesquisadores acadêmicos (academic track) e $40 \%$ de praticantes com conhecimento empírico de 28 países, com predominância de trabalhos das ciências sociais seguidos pela biomedicina, psicologia e saúde pública. Entre os principais desafios que resultaram do encontro, vários versam sobre recursos para pesquisas, o acesso à folha e ao cipó, a ortodoxia de alguns grupos ayahuasqueiros, entre outros. Neles não há menção alguma sobre demandas, conflitos ou reconhecimento das sociedades originárias, que constam como participantes do evento, mas não enquanto precursoras desses saberes. De fato, o que as falas encaminharam foram propostas de patrimonialização universal da ayahuasca.

5 Como um dos exemplos, ver Beltran (2014). 
institucional das igrejas ayahuasqueiras ali presentes $^{6}$. Os índios, enquanto convidados, emprestaram uma aura de "legitimidade" no cenário amazônico representado na sede do evento que, embora urbano e com comodidades, encontra-se relativamente próxima da floresta.

Foi baseado nessas experiências que, em assembleias regionais, os indígenas compreenderam a necessidade de utilizar outro formato de discussão orientado às suas problemáticas e que fosse conduzido pelos próprios, vetada a participação de cientistas e pesquisadores não indígenas.

\section{As inscrições}

Foram abertas inscrições eletrônicas para a participação na conferência, nas quais os interessados poderiam explicar suas intenções e que tipo de contribuição poderiam dar ao evento, que foram avaliadas por uma comissão que avaliou caso a caso sua pertinência. Além dos representantes de órgãos públicos que têm afinidade ao tema, como a Procuradoria da República, Iphan, Funai e a Polícia Federal, foram feitos convites alguns para não indígenas, entre eles eu, para "prestigiar e contribuir com este importante evento do movimento indígena do Vale do Juruá", conforme explicitado nos dizeres do convite.

A viagem de Cruzeiro do Sul até a Terra Indígena Puyanawa, em Mâncio Lima, dura aproximadamente uma hora pela rodovia BR-364, seguida por um pequeno trecho de estrada de terra. Os Puyanawa, após quase serem extintos no início do século XX, tornaram-se referência na produção de farinha de mandioca no Acre (macaxeira no nordeste brasileiro e atsá na língua Puyanawa), dotando a aldeia de uma infraestrutura que, junto à posição geográfica da aldeia, facilitou a logística do evento.?

Anteriormente à $1 .{ }^{a}$ Conferência Indígena da Ayahuasca, realizou-se entre 10 e 14 de dezem-

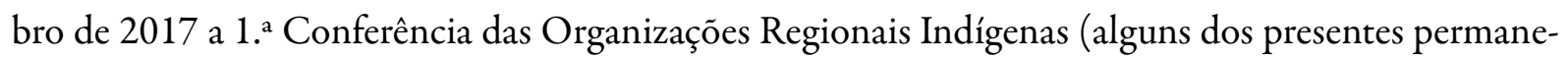
ceram na Conferência da Ayahuasca) para debater as diferentes políticas dos organismos oficiais que atuam no estado, particularmente com os representantes do governo estadual e de organizações não governamentais (ONGs) que atuam nesse contexto. Naquele momento também estavam presentes os parentes isolados contatados pela Frente de Proteção Etnoambiental do Envira - FPENV - (ali denominados como índios de recente contato) que participaram como observadores tímidos, talvez em sua primeira aparição numa assembleia de "parentes”.

As questões que estiveram em discussão diziam respeito às diversas dinâmicas das relações entre índios e não índios, principalmente aquelas relativas aos indígenas de recente contato, mas também apareceram questionamentos sobre a necessidade do protagonismo indígena nas tomadas de decisão e

6 Centro de Iluminação Cristã Luz Universal (Ciclu)/Alto Santo, Centro Rainha da Floresta (CRF), Centro de Iluminação Cristã Luz Universal Juramidã (Ciclujur), Centro Eclético Flor do Lótus Iluminado Maria Marques Vieira (Ceflimmavi), Centro Espírita Beneficente União do Vegetal (UDV), Centro Espírita e Culto de Oração Casa de Jesus - Fonte de Luz e Centro Espírita Obras de Caridade Príncipe Espadarte.

7 A exemplo de outras etnias no estado do Acre, os Puyanawa foram submetidos às sucessivas ondas invasoras de caucheiros, seringalistas e seringueiros. Forçados a aprender a língua portuguesa e abandonar seus costumes até a década de 1950 "viveram como verdadeiros escravos do Coronel Mâncio Lima, proprietário do seringal Barão do Rio Branco. Não tinham direito a nada, nem sequer a uma parte ínfima do seu antigo território. Foram completamente expropriados de suas terras. Passaram a fazer todos os tipos de trabalho braçal e pesado no seringal Barão e em troca recebiam a alimentação diária e umas poucas mudas de roupas." (Instituto Socioambiental ISA, 2010) fonte: ISA: <https://pib.socioambiental.org/pt/Povo:Puyanawa $>$. 
no planejamento de suas ações. Nas discussões apareceram aquelas ligadas à exploração de petróleo na Amazônia e nas terras indígenas da Amazônia, a profusão dos festivais culturais ${ }^{8}$ com suas vantagens e consequências, fortemente focadas na autodeterminação e na recusa de qualquer forma de tutela, seja explícita ou implícita.

Apesar de haver um reconhecimento do papel das ONGs, das iniciativas do governo do estado do Acre por meio dos processos de alfabetização indígena, produção e pesquisa, as falas foram contundentes no sentido de que "os índios não são de ninguém", com uma forte cobrança dos agentes ali presentes, governamentais ou não, sobre investimentos, retornos e a continuidade dos processos.

\section{A Yubaka Haiura}

A Conferência da Ayahuasca iniciou no dia 13 de agosto com uma apresentação musical dos anfitriões Puyanawa, liderados por seu cacique cantando uma canção (puya: sapos) chamando os outros animais da floresta. Após as boas vindas e demais apresentações formais, foram explicitadas as propostas de formato para o evento, sendo que, em seguida, iniciaram-se as falas.

Ainda durante a tarde do primeiro dia surgiu uma fala baseada na proposta original do encontro com relação ao protagonismo dos povos originários e o sigilo necessário para que se manifestassem de forma espontânea com relação a uma temática sensível e complexa. $\mathrm{Na}$ assembleia programática a questão do fim da tutela sobre a sua autodeterminação e protagonismo em relação a projetos, propostas e gerenciamentos de Ongs e governo foram evidenciados, inclusive com relação à educação escolar indígena. Ficou evidente a necessidade de produzir uma narrativa própria sobre a ayahuasca, a qual implica rejeitar também qualquer forma de tutela científica ou religiosa sobre a bebida.

Sendo um processo de construção e de tomada de posição, naturalmente ele passaria por discussões, contradições e posicionamentos conflitantes com relação a grupos, pessoas e instituições. Nesse sentido, para evitar a descontextualização das falas, foi realizada uma reunião com todos nawá (não índios) para estabelecer os limites e responsabilidades quanto ao registro das falas, performances e rituais. Nessa reunião, na presença de todos os nawá que pretendiam realizar registros, foi solicitado que todos assinassem um termo de confiabilidade e de cessão de direitos de todo material visual e auditivo captado para as Organizações Indígenas, além da necessidade de sua permissão para a utilização das falas, canções e imagens. Sem maiores questionamentos, todos os técnicos das agências governamentais presentes assinaram, além de outros profissionais participantes, como era o caso de uma equipe australiana que veio acompanhando um grupo de indígenas e um cinegrafista carioca que estava finalizando um documentário sobre a ayahuasca. Era permitido livremente à comissão de suporte do Ifac e a todos os indígenas o registro.

A conferência indígena pautou sua concepção e formato numa contraposição às premissas e resultados das edições da AYA. Nesse sentido, alguns pares comparativos evidenciam como elas motivaram as discussões e o formato do encontro, de alguma forma pensado como uma resposta desafiadora a cada um dos elementos que culminaram na Conferência Internacional da Ayahuasca, iniciando

8 Segundo o portal da Assessoria de Assuntos Indígenas do Governo do Acre são 48 festivais em todo o Estado. 
por sua denominação: uma Conferência Indígena em substituição à uma Conferência Internacional, apontando de partida os questionamentos sobre o que ali se compreendeu como mais um episódio de apropriação de conhecimentos, técnicas e ativos. Outros paralelos foram o protagonismo dos saberes indígenas em relação aos da academia, pesquisadores indígenas em relação aos pesquisadores brancos, a espacialidade provocativa do cenário da floresta na aldeia versus o urbano da universidade. E, fundamental para os organizadores, foram as apresentações dos palestrantes acontecendo quando $\mathrm{em}$ estado alterado de consciência após sua ingestão no lugar de discussões e diálogos sobre os estados alterados de consciência por meio de relatos, narrativas e entrevistas.

Baseada nessa rejeição ao que compreendem como apropriação de práticas dos povos originários sobre a ayahuasca, as falas questionaram pesquisadores acadêmicos que produzem conhecimento bioquímico, neurológico, sociológico ou religioso sobre o chá, mas não o bebem; os adeptos do neoxamanismo urbano que o consomem e comercializam promovendo práticas terapêuticas hibridas nos centros urbanos (Labate, 2002; 2017), respeitando de alguma forma o conhecimento indígena, mas advogando seu registro como patrimônio da humanidade e as Igrejas Daimistas tradicionais, tais como a UDV, a Barquinha e o Alto Santo.

Essas últimas, apesar de reconhecerem historicamente esse encontro transcultural (como no caso de Irineu Serra, fundador do Santo Daime), adquirem contornos mito- históricos (ver Goulart, 1996), crendo numa gênese com uma epistemologia "intercosmológica" na qual "os preceitos morais da doutrina são fundados no Novo Testamento Bíblico, o ritual tem origem indígena e a visão do mundo é espírita. “. A UDV também relata que uma das várias encarnações do Mestre Gabriel - fundador e recriador da doutrina -, foi numa tribo localizada no Peru em tempos incertos, que veio restaurar o vegetal (ayahuasca) na superfície da terra (Melo 2013). Em ambos os casos a materialidade da experiência com ayahuasca é suplantada por sua origem ancestral divina: os índios são portadores e não emissários ou protagonistas de sua origem.

Vale relatar brevemente aqui e de forma despretensiosa uma questão intersemiótica distintiva entre as diferentes percepções da ayahuasca, diacríticas para os vários segmentos que a utilizam. A narrativa do surgimento do Santo Daime nos dá pistas sobre isso, distinguindo seringueiros de procedência exógena e caboclos locais ${ }^{10}$ que são o resultado das relações entre os nawá e os indígenas, muitos dos quais naquele momento nos idos do final do século XIX em que, por conta das cruéis correrias ocorridas na região, viviam em situação de negação étnica. Desses últimos aprenderam não só o preparo da bebida, mas sua utilização lúdica nas noites de sábado no retorno das estradas de seringa, quando ao som do violão cantavam as chamadas dos "caboclo" (Goulart op. cit.: 4). Por "caboclo" pode-se compreender que não eram habitantes das cidades e nem tampouco índios: são aqueles homens e mulheres que se utilizaram muitas vezes dessa estratégia comum de se esconder, a partir dessa denominação genérica, das violências, perseguições e mortes provocadas principalmente pelas empresas seringalistas na região. Habitantes de mundo hibrido, lá e cá, funcionaram (e ainda funcionam) como uma ponte

9 Nesse sentido ver também Bomfim (2006).

10 Conhecidos como camamelucos em outras regiões do país, fruto dessa miscigenação entre índios e brancos, e também de "cabocos", sem a letra 1 . 
entre os vários mundos que naquele momento colidiam, trazendo e levando conhecimentos da floresta para a cidade e vice-versa.

A utilização da ayahuasca nos centros urbanos como um portal de "acesso ao sagrado", ou então em rituais de cura xamânicos, não é, de muitas formas, um traço comum às diversas etnias que dela se utilizam. Por exemplo os Kulina, falantes de uma língua Arawá e que vivem no Acre, sul do Amazonas e Peru, raramente a utilizam nos rituais de cura, preferindo o emprego do canto e da fala, enquanto que a ayahuasca é mais utilizada para localizar caça ou visitar parentes distantes. Já o povo Huni Kuin a utiliza, entre outras coisas, para defrontar-se com esse outro lado da realidade em que a espiritualidade também habita outros seres, animais ou plantas (Lagrou 1998).

Estudiosos de ayahuasca e plantas psicoativas como Hatsch (2005) argumentam que os estados alterados são profundamente influenciados tanto pela cosmologia pessoal como a coletiva dos usuários, operando como tipos diferenciados de mapa mental. Ele dirá que "a experiência que a droga produz é fortemente influenciada pela matriz cosmológica e mitológica do usuário, e pelo ritual que acontece no mundo exterior. Mitologia e cosmologia fornecem a topografia ou a cartografia do mundo xamânico além de mostrar os caminhos para dentro e para fora dele. Já o ritual fornece a estrutura externa que facilita a transição do usuário entre sua realidade cotidiana para a xamânica, e para ela voltar". ${ }^{11}$

Vários grupos Pano presentes na conferência, principalmente os Yawanawá e Huni Kuin, referem-se frequentemente à ayahuasca como medicina, ou como a "nossa medicina". Entre os xamãs Yawanawa reconhecidos (aqueles que fizeram as dietas e resguardos preparatórios) é comum a utilização de plantas, dietas e restrições alimentares para curar. De alguns mais velhos ouvi por mais de uma vez que os jovens que cantam e promovem sessões de uni nas aldeias e nas cidades ainda não são xamãs, por não terem completado sua iniciação, além de não conhecerem ou saberem utilizar as plantas curativas. O rapé, por exemplo, é muito difundido nessa região da Amazônia, utilizado ludicamente ou como instrumento de poder e de cura e pensando num contexto mais amplo, o xamanismo Pano utiliza mais o tabaco do que outras substâncias para curar e produzir o transe (Aparício 2017).

Também como resultado da popularização desse universo de práticas xamânicas com ayahuasca, que até recentemente configurava-se predominantemente masculino e adulto, é comum encontrar jovens e mulheres a utilizando, inclusive com alguns casos de xamãs femininas que são reconhecidas pelo seu grupo ${ }^{12}$.

Em um dos dois rituais de ayahuasca que ocorreu na conferência, uma das canções que os jovens cantaram, acompanhada por violão e percussão, faz referência a essa "força natureza que veio do astral colocando a pureza no meio da floresta, da Rainha Samaúma. E também as estrelas que encantam clareando." (trilha DR6:0.44), não passando despercebida aí a integração entre os saberes indígenas e

11 Em tradução livre: the drug experience is heavily influenced by the mythological and cosmological matrix of the user and by the ritual that is taking place in the external world. Mythology and cosmology provide the topography or cartography of the shamanic world and show the ways into it and back out. The ritual provides the outer framework that facilitates the user's transition from everyday reality to shamanic reality and back" (:27).

12 Entre os Yawanawá temos Putanny e Patsini Yawanawá reconhecidas como xamãs e outro caso entre os Manchineri do qual tenho apenas relatos orais. 
daimistas no contexto das trocas culturais religiosas acreana. Um exemplo dessas travessias inter-religiosas aparece numa das falas de Biraci Yawanawá, quando afirma que “... Jesus é o primeiro pajé. Deus é a natureza... a floresta o vento...."

As noções e concepções de "sagrado e profano", religioso e laico, são tanto controversas quanto sutis no universo ayahuasqueiro, seja ele indígena, urbano ou não. Essa discussão será brevemente levantada aqui apenas no sentido de sugerir que talvez para os indígenas não sejam apenas as doutrinas, morais ou legais, que estejam em pauta, senão um sentimento profundo, reincidente e antigo que se estende até a colonização europeia de ver e rever novamente suas práticas, conhecimentos e riquezas serem apropriadas sem o devido reconhecimento de sua origem.

Registro de patentes por indústrias farmacêuticas ou químicas, de substâncias ou de procedimentos tradicionais a elas ligados, direitos de uso de imagem e som negados ou desconsiderados e, nesse caso em tela, um tipo particular de biopirataria cultural dos conhecimentos e dos recursos genéticos desses povos originários, advogando o direito universal ao uso, registro universal e a disseminação mundial da ayahuasca sem que sejam consultados.

Em consonância com esse contexto mais amplo, todos os participantes foram instados, já no processo de inscrição para o encontro, a beber ayahuasca em algum momento, com uma frequência que variava de acordo com a vontade ou o interesse pessoal. Durante as exposições orais, vários oradores beberam o chá antes ou durante as sessões e, embora estivessem falando durante o estado alterado de consciência, isso era quase imperceptível para quem não soubesse ou tivesse presenciado a ingestão da bebida. Esse foi um divisor de águas entre as duas conferências, moldadas sobre cosmologias senão incompatíveis, quiçá excludentes.

Sem a participação de palestrantes nacionais ou estrangeiros, a conferência procurou organizar as discussões, os painéis, as cerimônias e celebrações, buscando caminhos próprios que também foram surgindo ao longo dos dias, movendo-se por entre os reflexos que essa medicina tem causado em todo mundo. Entre os participantes vale registrar gestores e autoridades presentes ao evento, entre eles juízes, procuradores, policiais federais e o comandante do Exército com alguns soldados (a instituição forneceu barracas de campanha para o evento), além de alguns convidados que têm ligação com os temas de indigenismo e ayahuasca, como é o meu caso.

Nos dias que se seguiram presenciei e registrei todas as discussões em que os vários povos presentes falaram abertamente sobre os mais variados temas relacionados ao chá, desde o plantio até sua patrimonialização, e entre eles um que particularmente me interessa, que é a relação dos cantos de ayahuasca enquanto interface entre domínios ontológicos não apenas entre seres visíveis e invisíveis, mas também entre um contínuo entre diferentes espécies e o papel dessas canções enquanto um tipo de idioma intercultural desses povos. O canto da abertura do encontro em formato de coro misto em uníssono dos Puyanawa criou um certo tipo de referência sonora para o encontro que era frequentemente lembrado pelos participantes. Essa é a impressão sonora (uma mistura em que o sonoro é registrado com pressão) que permanece em minha memória sobre esses dias de muita conversa, discussões, alegria e liberdade cultural. Numa das falas de Bira Yawanawá, ele disse que: - "Encontro de parente é igual namoro de jabuti: se bate, mas se entende". 
Ao longo dos debates que ocorreram sobre o uso, a liberação, o transporte, o reconhecimento da sabedoria dos povos da floresta e os perigos da sedução oportunista do mercado de consumo sobre os jovens xamãs, os indígenas falaram sempre o que quiseram, expuseram seus pontos de vista, discutiram, concordaram e discordaram, mas em momento algum abandonaram o respeito e a diplomacia cultural que tanto os distinguem. As falas finais foram sempre no sentido de procurar fazer o melhor, ser melhor, respeitar a si, os outros e a natureza que vive e é a própria floresta.

Os dias desenrolaram-se entre as falas das lideranças, o dia a dia na Terra Indígena, feito de dormir sobre o colchonete no chão duro, tomar vários banhos no igarapé e registrar as falas dos encontros numa oportunidade única de ouvir dos próprios atores diferentes relatos de etnogênese dos índios de recente contato, de demarcação de terras, de experiências místicas e a preocupação fundamental com as formas de lidar com a expansão do uso do cipó fora dos contextos nativos.

Apesar das várias temáticas e abordagens, é possível apontar algumas convergências nas diferentes falas, principalmente em relação ao receio de que essas apropriações culturais, bem-intencionadas ou não, venham ganhar contornos irremediáveis ou inelutáveis, seduzindo jovens indígenas desavisados para um mercado de raves praticado por adeptos de um certo tipo de "xamanismo de boutique", como disse em sua fala a representante do povo Tukano, a artista plástica Daiara Tukano.

Seguindo o fluxo perceptível das discussões e manifestações orais junto àquele invisível das mirações, era possível perceber um outro manifesto diariamente a partir de pequenos seres não humanos nativos. Ao monitorar os níveis de gravação do fluxo sonoro como sempre acontece em ambientes de floresta, pude captar uma intrincada sonoridade que formava a soundscape local (Krause, 2013) composta de grilos, macacos, pássaros e água, juntavam-se vozes humanas, violões, chocalhos, flautas, instrumentos percussivos e sotaques variadíssimos, desde o norte da China e Europa ${ }^{13}$ passando por xamãs latino-americanos, que vieram participar como ouvintes, até os jovens índios da região que passavam praticamente todas as horas do dia cantando canções de cipó, uni, rami, kamaräpi (todos nomes indígenas de ayahuasca) ou qualquer outra denominação particular utilizada no lugar do termo genérico ayahuasca. Nesse ambiente multicultural ouvi canções Kayapó Gorotire do Xingu junto a ícaros da Amazônia Peruana, cantadas junto a hinários do Santo Daime acompanhados por violão e percussão.

Durante as noites do encontro, ocorreram projeções de documentários e curtas com temática indígena ou ayahuasqueira. Numa delas foi projetado o documentário Xinã Bena Beisikit, de Dedê Maia, com narração do txai Terry Aquino, que disparou: - Eu adoro Haux Music! (haux, numa definição bastante simplificada, é uma palavra sagrada usada por alguns grupos indígenas para iniciar e fechar seus rituais, mas nesse caso a referência remete a uma localidade, a um povo ou uma tradição desses povos de língua pano do Acre).

Durante o evento, aconteceram duas sessões oficiais de ayahuasca que foram organizadas da seguinte forma: durante a primeira parte os antigos xamãs cantavam seus cantos desacompanhados, em formato solo ou coletivo e, após a segunda dose, os jovens surgiam para cantar suas canções acompanhadas por instrumentos, fossem violões, chocalhos ou tambores sem uma formação rígida. Essa é a Haux Music.

13 Participaram do evento um sueco, um italiano, um indiano e uma chinesa. 
Velhos, jovens e lideranças indígenas compreendem que são estilos cancionais distintos entre cantos com e sem acompanhamento de instrumentos, nesse caso os de origem não indígena, significando e indicando uma fronteira que precisa ser melhor compreendida entre o novo e o tradicional, o misturado e o puro, jovens e velhos. Embora se respeitem, o repertório tradicional é bastante distinto das novas manifestações. ${ }^{14}$

Duas performances realizadas durante a primeira sessão da ayahuasca, que aconteceu no interior de um galpão da aldeia, chamaram-me a atenção, sendo o primeiro deles um canto Puyanawa realizado na abertura, em coro uníssono e desacompanhado. Duas características que hoje tendo a considerar diacríticas das manifestações musicais desacompanhadas dessa região ocorreram durante sua execução, que foram o pitch rising e pulse rising, alterando simultânea e coletivamente tanto a frequência como o pulso. Ao final, quando a canção e os cantores retornam ao ponto de partida, a frequência aumentou quase um tom e meio, o pulso mais de $20 \%$ e dinâmica passou de mezzo forte para fortíssimo, produzindo uma sensação de habilidade técnica para os que ouviam.

A segunda foi uma canção de kawá (a folha que se mistura ao cozimento do cipó) executada por Biracy Yawanawa. Diferentemente da canção coletiva Puyanawa, era uma canção solista que evidenciava a qualidade interpretativa do cantor. Sentado no chão com roupas cerimoniais, ele iniciou um canto preciso e suave com voz de barítono, desenhando um fio labiríntico por meio das palavras, do som e de sua movimentação no salão. Com habilidade construiu uma performance delicada e firme, natural e formal, como é o próprio kene (os desenhos geométricos em Huni Kuin).

\section{Resultados e proposições da conferência}

Ao final do encontro foi elaborado um documento chamado Carta de Recomendação Interna, com as deliberações do encontro que, de imediato, apontam a necessidade de um movimento de retorno da discussão às aldeias para que junto às lideranças debatam e proponham soluções, questões e pautas para a 2. ${ }^{a}$ Conferência Indígena da Ayahuasca, planejada para acontecer em agosto de 2018.

São inúmeras as recomendações da carta: desde o resgate dos diferentes povos do conhecimento do uso tradicional da medicina no passado; os limites de compartilhamento desse conhecimento com os não indígenas; a criação de cursos de formação de utilização de plantas medicinais; a definição de direitos autorais sobre as músicas de uni; uma resolução de usar os nomes nativos ao invés do nome genérico de ayahuasca; redefinir com as autoridades a excessiva fiscalização de medicinas indígenas pelos agentes públicos durante as viagens de xamãs para fora das aldeias; incluir a presença de pajés na comissão do Iphan no processo de avaliação de registro da ayahuasca como patrimônio cultural brasileiro junto às igrejas daimistas e criar um processo próprio de avaliação do registro da ayahuasca como patrimônio cultural dos povos indígenas.

Uma das grandes expectativas da conferência foi sobre o processo de patrimonialização da ayahuasca em nome das populações originárias, que poderia gerar para os indígenas segurança jurídica ou patentes. O Iphan, por intermédio de seu coordenador geral de identificação e registro, Deyvesson

14 Esse assunto é importantíssimo e será devidamente aprofundado em outro momento. 
Israel Alves Gusmão, respondeu a esses questionamentos no sentido de que a caracterização de patrimônio cultural não equivale a patente genética, não estabelecendo nenhum tipo de direito comercial ou autoral. As consultorias do Iphan apontaram então no sentido do reconhecimento da ayahuasca a partir da forma como ela se manifesta, ou seja, por meio dos cantos, da ritualística e da visualidade ilustrada por pinturas e desenhos. Algumas falas procuraram situar o debate fora do eixo específico da discussão, argumentando que os povos originários são igualmente portadores de conhecimentos originários entre os quais a ayahuasca é fundamental, mas não exclusiva. Porém reconheceu-se que, nas esferas em que se instanciavam, essa discussão não tinha como ser feita.

Embora o documento com as deliberações e discussões seja extenso na sua forma, ele é sintético em relação ao seu conteúdo, remetendo boa parte da discussão à proteção dos direitos originários indígenas e às consequências da expansão do uso do chá entre não indígenas. Essas informações estão no documento produzido pela comissão organizadora da conferência, que pode ser acessado diretamente por meio das Associações Indígenas e da Funai. Ao final, o documento pareceu-me de alguma forma consistente e coerente com a proposta da conferência procurar demonstrar o processo de construção da Yubaka Haiura, em que todos procuraram conversar muito sobre o que é certo de se fazer sobre a ayahuasca e, a partir dele, criar, pacientemente, um grande movimento.

Domingos Bueno da Silva é professor de Música na Universidade Federal do Acre - UFAC. Mestre em Antropologia pelo PPGAS/UFSC e doutorando em Antropologia no PPGA/UFPR. 


\section{REFERÊNCIAS BIBLIOGRÁFICAS}

APARICIO, Miguel. 2017. A explosão do olhar: do tabaco nos Arawa do Rio Purús. Mana 23(1): 09-035.

BELTRÁN, R. Un congreso convierte a Ibiza en la capital mundial de la ayahuasca, 2014. Disponível em: https://www.noudiari.es/2014/03/un-congreso-convierte-ibiza-en-la-capital-mundial-de-la-ayahuasca. Acesso em 01 de junho de 2018.

BOMFIM, Juarez Duarte. 2006. O Jardim de Belas Flores. Do mestre Raimundo Irineu Serra. Salvador. Disponível em: http://www.mestreirineu.org/livro_juarez.pdf . Acesso em 20 de novembro de 2018.

GOULART, Sandra Lucia. 1996. As Raizes Culturais do Santo Daime. Dissertação de Mestrado (Ciências Sociais - Antropologia): USP.

GROISSMAN, Alberto. 1991. "Eu venho da floresta”: ecletismo e práxis xamânica daimista no "Céu do Mapia”, Dissertação de Mestrado: UFSC.

KRAUSE, Bernie. 2013. A grande orquestra da natureza. Rio de Janeiro: Zahar.

LABATE, Beatriz Caiuby; ARAÚJO, Wladimyr Sena (Org.). 2002. O uso ritual da ayahuasca. Campinas: Mercado das Letras.

LABATE, Beatriz Caiuby; GOLDSTEIN, Ilana. 2017. "Encontros Artísticos e Ayahuasqueiros: Reflexões sobre a colaboração entre Ernesto Neto e os Huni Kuin”. Mana, 23(3): 437-471.

LAGROU, Elsje Maria. 1998. Caminhos, duplos e corpos: uma abordagem perspectivista da identidade e alteridade entre os Kaxinawá. Tese de Doutorado (Ciências Sociais - Antropologia). São Paulo: USP.

LUNA, Luis Eduardo. 1986. Vegetalismo: Shamanism among The Mestizo Population of The Peruvian Amazon. Stockholm: Almquist.

MELO, Rosa Virgínia. 2013. "Encantamento e disciplina na União do Vegetal”, Anuário Antropológico /2012-I: 217-237.

MIZUMOTO, Suely Akimi. 2012. Dissociação, Religiosidade e Saúde: um estudo no Santo Daime e na Umbanda. Dissertação de Mestrado, São Paulo: USP.

RÄATSCH, Christian. 2005. The encyclopedia of psychoactive plants: ethnopharmacology and its applications. USA: Park Street Press.

RECEBIDO: $08 / 06 / 2018$

APROVADO: $27 / 08 / 2018$ 
194 CAMPOS V.19 N.1 jan.jun.2018 